\title{
Polarity and epithelial-mesenchymal transition of retinal pigment epithelial cells in proliferative vitreoretinopathy
}

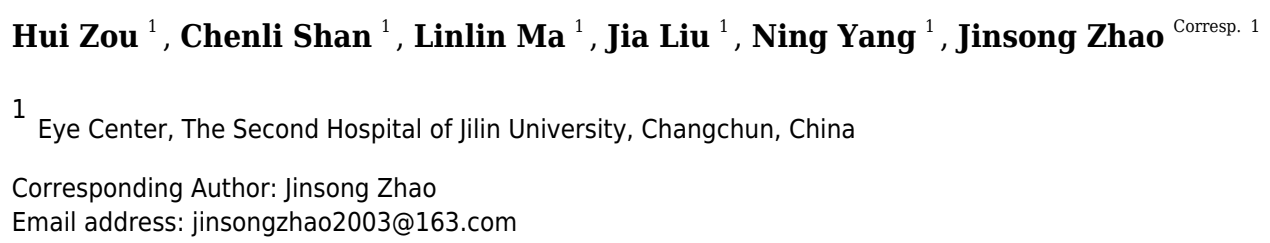

Under physiological conditions, retinal pigment epithelium (RPE) is a cellular monolayer composed of mitotically quiescent cells. Tight junctions and adherens junctions maintain the polarity of RPE cells, and are required for cellular functions. In proliferative vitreoretinopathy (PVR), upon retinal tear, RPE cells lose cell-cell contact, undergo epithelial-mesenchymal transition (EMT), and ultimately transform into myofibroblasts, leading to the formation of fibrocellular membranes on both surfaces of the detached retina and on the posterior hyaloids, which causes tractional retinal detachment. In PVR, RPE cells are crucial contributors, and multiple signaling pathways, including SMADdependent pathway, Rho pathway, MAPK pathways, Jagged/Notch pathway, and Wnt/ $\beta$ catenin pathway, are activated. These pathways mediate the EMT of RPE cells, which play a key role in the pathogenesis of PVR. This review summarizes the current body of knowledge on the polarized phenotype of RPE, the role of cell-cell contact, and the molecular mechanisms underlying the RPE EMT in PVR, emphasizing key insights into potential approaches to prevent PVR. 
1

2 Polarity and Epithelial-mesenchymal Transition of

3 Retinal Pigment Epithelial Cells in Proliferative

4 Vitreoretinopathy

5

6

7 Hui Zou ${ }^{1}$, Chenli Shan ${ }^{1}$, Linlin Ma ${ }^{1}$, Jia Liu ${ }^{1}$, Ning Yang ${ }^{1}$, Jinsong Zhao ${ }^{1}$

8

9

10

11 Corresponding Author:

12 Jinsong Zhao;

13 Eye Center of the Second Hospital, Jilin University, 4026 Yatai Street, Changchun, Jilin,

14 130021, China

15 Email address: jinsongzhao2003@163.com

16

17

18

19

20

21 
Abstract

Under physiological conditions, retinal pigment epithelium (RPE) is a cellular monolayer composed of mitotically quiescent cells. Tight junctions and adherens junctions maintain the polarity of RPE cells, and are required for cellular functions. In proliferative vitreoretinopathy (PVR), upon retinal tear, RPE cells lose cell-cell contact, undergo epithelial-mesenchymal transition (EMT), and ultimately transform into myofibroblasts, leading to the formation of fibrocellular membranes on both surfaces of the detached retina and on the posterior hyaloids, which causes tractional retinal detachment. In PVR, RPE cells are crucial contributors, and multiple signaling pathways, including SMAD-dependent pathway, Rho pathway, MAPK pathways, Jagged/Notch pathway, and Wnt/ $\beta$-catenin pathway, are activated. These pathways mediate the EMT of RPE cells, which play a key role in the pathogenesis of PVR. This review summarizes the current body of knowledge on the polarized phenotype of RPE, the role of cellcell contact, and the molecular mechanisms underlying the RPE EMT in PVR, emphasizing key insights into potential approaches to prevent PVR.

\section{Introduction}

Proliferative vitreoretinopathy (PVR) is a complex blinding disease that occurs after rhegmatogenous retinal detachment (RRD), surgical interventions, or ocular trauma. As a prolonged and exaggerated scarring process, PVR is characterized by the formation of contractile fibrocellular membranes in the vitreous cavity and on the inner and outer surfaces of the retina (Committee 1983; Mudhar 2020; Tosi et al. 2014). At present, surgical interventions, including vitrectomy, membrane peeling, pneumatic retinopexy, and scleral buckle, remain the mainstay of treatment in PVR. Although work in recent decades has led to advancements in surgical techniques and management, PVR cannot be effectively treated and is still the most common cause of failure to reattach the retina (Coffee et al. 2014; Khan et al. 2015; Mitry et al. 2012; Wickham et al. 2011). In addition, in spite of successful anatomic reattachment, the visual function of such cases cannot be improved, due to the retinal damage resulting from the mechanical contraction of fibrous membranes. Therefore, in order to improve postoperative visual function and reduce the incidence of this serious complication, it is particularly important to explore new prophylactic and therapeutic approaches based on a deeper understanding of the pathogenesis of PVR. 
A growing body of evidence indicates that the mechanisms of PVR are orchestrated by multiple elements (Idrees et al. 2019; Jin et al. 2017; Pastor et al. 2016), such as growth factors (Charteris 1998; Ni et al. 2020; Pennock et al. 2014; Wubben et al. 2016), cytokines (Bastiaans et al. 2018; Harada et al. 2006; Limb et al. 1991), extracellular matrix proteins (Feist et al. 2014; Miller et al. 2017) and various cells (Eastlake et al. 2016; Pennock et al. 2011; Shu \& Lovicu 2017). According to the histopathology of PVR, the fibrocellular membrane of PVR is composed of excessive extracellular matrix (ECM) and multiple types of cells, and retinal pigment epithelial (RPE) cells have been indicated as the most consistently present and the most abundant (Amarnani et al. 2017; Ding et al. 2017; Hiscott et al. 1989; Machemer \& Laqua 1975), proving that the RPE cell plays a crucial role in PVR. Under physiological condition, the polarized RPE cell is non-proliferative by cell-cell contact. However, when the eye suffers from a retinal break or trauma, RPE cells are exposed to various growth factors and cytokines that are produced by activated immune cells, leading to the disruption of junctional complexes in RPE cells. Subsequently, activated RPE cells detach from Bruch's membrane, migrate through the defect of the retina, proliferate, and transform into myofibroblasts, forming fibrotic membranes (Chen et al. 2015; Morescalchi et al. 2013; Palma-Nicolás \& López-Colomé 2013). In an analogous process to exaggerated wound healing response, these membranes can attach to the retina and contract, resulting in further retinal detachment and poor vision (Chiba 2014; Garweg et al. 2013). It is noteworthy that due to the loss of cell-cell contact, RPE cells undergo epithelialmesenchymal transition (EMT), which is pivotal in the development of PVR. During EMT, RPE cells transdifferentiate into mesenchymal cells that are characterized by increased motility, and enhanced ability to proliferate, resist apoptosis and produce extracellular matrix proteins, thus participating in PVR (Tamiya \& Kaplan 2016; Zhang et al. 2018c). These indicate that in-depth knowledge of EMT may provide insight into potential approaches to prevent PVR. Therefore, this review focuses on the polarized phenotype of RPE and molecular mechanisms of RPE cell EMT, discussing the role of RPE cells in PVR.

\section{Survey methodology}

We used the PubMed database to search available literature based on keywords including "proliferative vitreoretinopathy(PVR)" and "retinal pigment epithelial cell". To include more information on the polarity of RPE, we also searched articles about the structure and function of cell-cell junctions in RPE cells that explored the role of cell-cell contact in EMT.

\section{The Polarized Retinal Pigment Epithelial Cell}

The human RPE cell achieves terminal differentiation at four to six weeks of gestation and subsequently remains mitotically quiescent (Lutty \& McLeod 2018; Stern \& Temple 2015). The RPE, which is situated between the photoreceptors and the choroid, plays many complex roles 
94

95

96

indispensable to the health of the neural retina and the choroid. These roles include recycling of components of the visual cycle, absorption of light to protect from photo-oxidative stress, production of essential growth factors, immunological regulation of the eye, phagocytosis of photoreceptor outer segments generated during daily photoreceptor renewal, and transportation across the blood retina barrier (BRB) (Ferrington et al. 2016; Fields et al. 2019; Mateos et al. 2014; Naylor et al. 2019; Strauss 2005; Vigneswara et al. 2015). In order to maintain these multiple functions, RPE cells display a highly specialized structural and functional polarity.

Similar to other epithelia, the RPE displays three characteristics of the epithelial phenotype: apical plasma membrane, junctional complexes, and basolateral domain. RPE cells display structural polarity, with apical microvilli and melanosomes, and basal microinfolds. The abundant melanin granules in RPE cells absorb stray light, a process that is essential for visual function (Strauss 2005). In a polarized cell, the distributions of surface proteins on the apical and basal plasma membranes are different, contributing to the performance of cellular functions (Khristov et al. 2018). However, a highly polarized distribution of ion channels, transporters and receptors in RPE is different from that observed in conventional extraocular epithelia (Lehmann et al. 2014). For example, Na, K-ATPase(Sonoda et al. 2009) and monocarboxylate transporters (MCT) 1(Deora et al. 2005) are localized to the apical aspect of RPE cells, while chloride transporter CFTR(Maminishkis et al. 2006) is basally located. On the apical plasma membrane, RPE cells phagocytize the photoreceptor outer segments, which are regulated by polarized receptors. Bulloj et al. (2018) found that binding of Semaphorin 4D (sema4D) to RPE apical receptor Plexin-B1 suppresses outer segment internalization, contributing to the maintenance of photoreceptor function and longevity. The RPE also transports fluid out of the subretinal space, and regulates bidirectional nutrient transport between the outer retina and the choroid, in a manner dependent on the polarized distribution of membrane channels and transporters(Strauss 2005). The RPE basolaterally secretes extracellular matrix components and factors, which participate in ECM remodeling and maintain the outer BRB (oBRB) function (Caceres \& Rodriguez-Boulan 2020). Therefore, the polarized phenotype of the RPE is vital to both the $\mathrm{oBRB}$ and is the basis of the homeostasis of the outer retina (Caceres \& Rodriguez-Boulan 2020; Lehmann et al. 2014). The disruption of RPE polarity contributes to the development of several retinal diseases, such as PVR and age-related macular degeneration (AMD). A comprehensive understanding of the way in which this polarity is achieved may provide insights into the pathogenesis of PVR.

However, most available data on RPE polarity is contributed by studies performed on RPEimmortalized cell lines that show partial preservation of the RPE phenotype, and were extrapolated from data obtained from the prototype Madin-Darby Canine Kidney (MDCK) cell line (Lehmann et al. 2014). The detailed mechanisms that determine RPE polarization remain 
130

131

132

133

134

135

136

137

138

139

140

141

142

143

144

145

146

147

148

149

150

151

152

153

154

155

156

157

158

159

160

161

162

163

164

165

unclear. Some scholars believe that junctional complexes, including adherens junctions (AJs) and tight junctions (TJs), are essential for building epithelial cell polarity and maintaining the integrity of epithelial layers such as RPE (Niessen 2007; Pei et al. 2019; Tamiya \& Kaplan 2016).

Tight junctions are complex cell-cell junctions formed by transmembrane proteins interactions with peripheral cytoplasmic proteins (Fig 1). Transmembrane proteins include occludin, members of the claudin family, and junctional adhesion molecules (JAMs). Peripheral cytoplasmic proteins, such as zonula occludens (ZOs), form bridges between transmembrane proteins and the actin filament cytoskeleton and play a key role in the assembly and organization of TJs (Bazzoni \& Dejana 2004; Bazzoni et al. 2000; Naylor et al. 2019).

The RPE tight junctions regulate the paracellular movement of solutes via size and charge selectivity (Benedicto et al. 2017; Caceres et al. 2017; Naylor et al. 2019).Occludin and claudins determine the permeability and semi-selectivity of the TJs, and as such play critical roles in the oBRB (Balda et al. 2000; Fields et al. 2019; Furuse et al. 1998; Günzel \& Yu 2013; Rosenthal et al. 2017). JAMs regulate TJ assembly and function by recruiting other proteins to the TJ and play an important role in the barrier property of TJs (Balda \& Matter 2016; Orlova et al. 2006; Shin et al. 2006). In patients with RRD, damage to TJs elicits the breakdown of oBRB and promotes the penetration of growth factors and cytokines, aggravating PVR. As well as having a barrier function, TJs define the physical separation between apical and basal domains of the plasma membrane, to maintain RPE cell polarity (Campbell et al. 2017; González-Mariscal et al. 2014; Sluysmans et al. 2017). The two extracellular loops of occludin mediate adhesion of adjacent cells and block the movement of plasma components. The C-terminal domain combines directly with ZOs, subsequently interacting with the actin cytoskeleton, which is essential to organizing and maintaining cell polarization (Balda \& Matter 2016; Furuse et al. 1994; Shin et al. 2006; Tarau et al. 2019). Feng et al. (2019) demonstrated that during EMT, the breakdown of TJs resulting from loss of claudin-1 causes ARPE-19 cells to lose their epithelial phenotype and transform into fibroblasts, promoting the development of PVR. TJs are involved in the regulation of signaling pathways that govern various cellular functions such as proliferation, migration, and differentiation (Bhat et al. 2018; Shi et al. 2018; Sluysmans et al. 2017). Vietor et al. (2001) found that decreased amounts of occludin can cause up-regulation and translocation of the adhesion junction protein $\beta$-catenin, which interacts with the transcription factor lymphoid enhancer-binding factor (LEF)/T cell factor (TCF) in the nucleus, leading to a loss of the polarized epithelial phenotype in $\mathrm{EpH} 4$ cells. ZOs, adaptor proteins within the TJ complex, exhibit dual localization at TJs and in the nucleus. Under injury or stress, the disruption of TJs increases ZO-2 nuclear accumulation, driving its interaction with transcription factors, and inducing MDCK epithelial cell proliferation (Islas et al. 2002; Shi et al. 2018; Traweger et al. 
166

167

168

169

170

171

172

173

174

175

176

177

178

179

180

181

182

183

184

185

186

187

188

189

190

191

192

193

194

195

196

197

198

199

200

201

2003). In differentiated RPE cells, the interaction between ZO-1 with ZO-1-associated nucleic acid-binding protein (ZONAB) maintains cell-cell contact by sequestering ZONAB at the TJ or in the cytoplasm, maintaining cells dormancy. However, when damage to TJs decreases ZO-1 levels, ZONAB is translocated into the nucleus, leading to the up-regulation of cyclin D1 (CD1) and subsequent cell proliferation (Balda et al. 2003; González-Mariscal et al. 2014). Therefore, TJs provide a structural foundation for the maintenance of cell-cell contact. Georgiadis et al. (2010) demonstrated that the overexpression of ZONAB or knockdown of ZO-1 could result in increased RPE proliferation and the development of EMT. Recent research has confirmed that during EMT, ZO-1 is decreased in ARPE-19 cells, and the knockdown of either ZO-1 or AJ protein E-cadherin leads to the downregulation of the other protein, indicating the existence of an interaction between the two junctional complexes (Bao et al. 2019). Due to the importance of TJs in the maintenance of integrity and functionality of epithelial cells, several researchers have focused on novel factors that stimulate the formation of TJs, such as nicotinamide (Hazim et al. 2019) and lysophosphatidic acid (Lidgerwood et al. 2018). Studies into these factors may produce well-differentiated RPE cell lines and a platform to enable the rapid expansion of our understanding of many RPE functions and retinal pathologies. This approach could be conducive to finding novel therapeutic interventions for PVR.

Besides the TJ complex described above, another type of junctional complex called AJs plays a key role in the maintenance of the integrity of epithelial cells and cell-cell contact (Fig 1). Cadherins, the major proteins of AJs, belong to the glycoprotein superfamily, of which there are more than 20 members. The cytoplasmic domain of cadherins regulates interactions between cadherins and catenins, including $\beta$-catenin, $\alpha$-catenin, and p120-catenin, and other scaffolding proteins such as ZO-1, to maintain cell shape and modulate cell proliferation (Aberle et al. 1994; Nelson \& Nusse 2004; Wheelock \& Johnson 2003). In quiescent adult RPE cells, epithelial cadherins (E- and/or P-cadherin) sequester $\beta$-catenin at the AJs to maintain cell-cell contact. Reduction of cadherin levels or dissociation of AJs allows $\beta$-catenin to translocate into the nucleus, where it interacts with the transcription factor LEF, and activates the transcription of various genes, including Snail and cyclin D1, which participate in RPE cell EMT via the canonical Wnt/ß-catenin signaling pathway (Gonzalez \& Medici 2014; Lamouille et al. 2014; Nelson \& Nusse 2004; Yang et al. 2018). Tamiya et al. (2010) suggested that the loss of Pcadherin causes the loss of cell-cell contact and initiates RPE cell migration and EMT. These events coincide with a switch in cadherin isoform expression from P- to N-cadherin. In addition, hepatocyte growth factor (HGF) and its receptor c-Met can destabilize cell-cell adhesion and elicit nuclear translocation of $\beta$-catenin, resulting in RPE cell migration (Lilien \& Balsamo 2005; Liou et al. 2002). Jin et al found that HGF induces loss or redistribution of junctional proteins ZO-1, occludin, and $\beta$-catenin in RPE explants, potentially damaging barrier function and 
202

203

204

205

206

207

208

209

210

211

212

213

214

215

216

217

218

219

220

221

222

223

224

225

226

227

228

229

230

231

232

233

234

235

236

increasing the migration of RPE cells, resulting in retinal detachment(RD) and PVR (Jin et al. 2002; Jin et al. 2004). Given the importance of HGF in the interruption of RPE junction, HGF may be a potential target for the prevention and treatment of PVR. However, this possibility needs further study.

Under physiological conditions in the eye, TJs and AJs maintain the specialized structural and functional polarity of RPE cells and play a pivotal role in the maintenance of cell-cell contact; they sequester EMT signaling effectors ZONAB and $\beta$-catenin at the junction or cytoplasm to prevent cells from responding to mitotic factors, causing cells to leave the cellcycle (Fig 1). Thus, normally, RPE cells form a cobblestone-like monolayer of immotile, polarized, and mitotically quiescent cells. However, once junctional complexes break down, RPE cells undergo EMT, which is an important contributor to proliferative vitreoretinopathy. In this pathological process, RPE cells lose their structural and functional polarity and transdifferentiate into mesenchymal cells, which proliferate, resist apoptosis, possess migratory ability, and produce abundant ECM, leading to the formation of an aberrant scar-like fibrocellular membrane.

\section{De-differentiated RPE and Fibrocellular Membrane}

Proliferative vitreoretinopathy is characterized by the formation of fibrocellular membranes composed of proliferative and migratory cells and excessive, aberrant ECM. Histopathological analysis of PVR has demonstrated that PVR membranes have contractile activity and strain the retina, leading to tractional retinal detachment (TRD), which is responsible for blurring vision.

Several studies (Feist et al. 2014; Takahashi et al. 2010) have found that the cellular components of PVR membranes include RPE cells, myofibroblasts, fibroblasts, glial cells and macrophages, and that myofibroblasts are critical for the formation and contractile activity of fibrocellular membranes. Based on the indirect immunofluorescence evaluation of human PVR membranes, Feist et al. (2014) showed that myofibroblasts originate principally from RPE cells through EMT. Myofibroblasts are characterized by increased expression of alpha-smooth muscle actin ( $\alpha$-SMA) and incorporation of $\alpha$-SMA into newly formed actin stress fibers, which enhances their contractile properties. Myofibroblasts also secrete excessive matrix and profibrogenic factors, promoting the contraction of PVR membranes that ultimately cause irreversible loss of vision (Gamulescu et al. 2006; Hinz et al. 2001; Shu \& Lovicu 2017; Tamiya \& Kaplan 2016; Tomasek et al. 2002).

In addition to myofibroblasts, abnormally increased ECM reinforces the continuous contractile tension of PVR membranes, and this mechanical tension, together with specialized ECM proteins, regulates myofibroblast differentiation and its function, contributing to PVR. In PVR membranes, the primary components of ECM are collagen and fibronectin. The majority of 
237

238

239

240

241

242

243

244

245

246

247

248

249

250

251

252

253

254

255

256

257

258

259

260

261

262

263

264

265

266

267

268

269

270

271

collagen fibrils are type I collagen, which is synthesized by RPE cells and Müller cells. Collagen fibrils provide tensile strength to the ECM, and activate Rho, resulting in the translocation of myocardin-related transcription factor (MRTF) into the nucleus and promoting RPE cell EMT (Guettler et al. 2008; Miralles et al. 2003). Fibronectin may also play a significant role in PVR. During pathological ECM remodeling, fibronectin is one of the earliest ECM components recruited, serving as a scaffold for other ECM proteins (Kadler et al. 2008; Miller et al. 2017; Miller et al. 2014). Extra domain (ED)-A fibronectin, a splice variant of fibronectin, is increased in TGF- $\beta 2$-induced RPE cells and induces myofibroblast differentiation, participating in PVR (Khankan et al. 2011).

Under normal conditions, ECM breakdown by proteases such as matrix-metalloproteases (MMPs) plays a crucial role in ECM remodeling and the release of growth factors, maintaining tissue homeostasis in cooperation with ECM synthesis, reassembly, and chemical modification (Bonnans et al. 2014; Craig et al. 2015; Lindsey et al. 2016). As mentioned above, the polarized RPE is able to basolaterally secrete the extracellular matrix components fibronectin and collagens, MMP and tissue inhibitors of MMPs (TIMPs), which participate in ECM remodeling. However, under pathological conditions such as inflammation and retinal injury, RPE cells lose their apical-basal polarity, undergo EMT and abnormally secrete MMPs, TIMPs and ECM proteins, leading to dysregulated ECM remodeling (Greene et al. 2017). Such ECM has aberrant composition and organization and mechanical properties, and enhances matrix stiffness and strain, which disrupts the normal structure and function of the retina, exacerbating the progression of PVR.

\section{RPE and Epithelial-mesenchymal Transition}

\subsection{EMT of RPE Cell}

Epithelial-mesenchymal transition is an important biological process, in which epithelial cells transdifferentiate into mesenchymal cells. Although EMT can occur in normal embryonic development and wound healing, it also participates in pathological processes such as fibrosis, cancer progression, and PVR. There are three distinct subtypes of EMT: type 1 occurs during tissue and embryo development, type 2 is involved in wound healing and organ fibrosis, and type 3 is associated with cancer progression and metastasis (Dongre \& Weinberg 2019; Kalluri \& Weinberg 2009). This review focuses on type 2 EMT, which is crucial to PVR. During EMT, due to junctional complexes damage, RPE cells relinquish their apical-basal polarity, reorganize their cytoskeletal architecture, and convert into spindle-shaped cells (Fig 1). These cells downregulate the expression of epithelial proteins such as E-cadherin and ZO-1, and increase expression of mesenchymal drivers including $\mathrm{N}$-cadherin, vimentin, $\alpha$-SMA and fibronectin ( $\mathrm{Li}$ et al. 2020). This mesenchymal transdifferentiation of RPE cells can increase the directional 
272 motility of individual cells, confer resistance to apoptosis, and facilitate cell proliferation and 273 dysregulated ECM remodeling, eventually leading to the formation of PVR membranes.

\subsection{Transcription Factors of EMT}

275

276

277

278

279

280

281

282

283

284

285

286

287

288

289

290

291

292

293

294

295

296

297

298

299

300

301

302

303

304

305

306

The details of the molecular mechanisms that drive RPE cell EMT and lead to PVR remain to be clarified. Emerging evidence suggests that diverse extracellular inductive signals, including soluble cytokines and growth factors, and ECM components, can modulate the expression and activity of EMT-associated transcription factors and act together to control the initiation and progression of EMT in responding epithelial cells (Yang et al. 2020). Among the various transcription factors involved in the induction of EMT, core transcription factors including Snail 1, Snail 2(also known as Slug), Twist 1 and zinc-finger E-box-binding (Zeb) 1 have been identified as important regulators of RPE cell EMT. These factors impact the expression of genes that control repression of the epithelial phenotype and activation of the mesenchymal phenotype (Boles et al. 2020; Feng et al. 2019; Li et al. 2019; Li et al. 2014; Liu et al. 2009; Palma-Nicolás \& López-Colomé 2013). For example, thrombin can repress the expression of E-cadherin by stimulating Snail 2 expression and promote the expression of $\mathrm{N}$-cadherin by phosphoinositide 3kinase (PI3K)/PKC-ל/mTOR signaling in Rat RPE cells (Palma-Nicolás \& López-Colomé 2013). During RPE dedifferentiation in primary culture, Zeb1 is overexpressed and binds to the MITF A promoter to repress the cyclin dependent kinase inhibitor, p21CDKN1a, resulting in RPE cell proliferation and EMT (Liu et al. 2009). These EMT transcription factors often act in concert, functionally cooperating at target genes by the convergence of signaling pathways. However, the molecular details of how these transcription factors contribute to EMT are still elusive (Lamouille et al. 2014; Stone et al. 2016).

\subsection{Epigenetic Factors of EMT}

Due to the importance of epigenetic regulation of EMT, epigenetic modifiers have attracted increasing attention. Evidence has shown that epigenetic modifiers work in concert with transcription factors at different molecular layers to regulate the EMT process (Skrypek et al. 2017). Several epigenetic factors have been described including DNA methylation, histone modification and non-coding RNA. Because of the specific machinery utilized for EMT activation, these modifications are characterized by cell type specificity. In RPE cells, MethylCpG-binding protein 2 (MeCP2), a DNA methylation reader, plays a crucial role in the induction of EMT, and DNA methylation may participate in the pathogenesis of PVR (He et al. 2015; Li et al. 2020). He et al. (2015) found high levels of expression of MeCP2 in all human PVR membranes, and concluded that MeCP2 mediates $\alpha$-SMA expression through Ras GTPase activating protein (RASAL1). Furthermore, DNA methylation inhibitor 5-Aza-2' deoxycytidine (5-AZA-dC) reportedly inhibits the expression of TGF- $\beta$-induced $\alpha$-SMA and FN in human fetal 
307

308

309

310

311

312

313

314

315

316

317

318

319

320

321

322

323

324

325

326

327

328

329

330

331

332

333

334

335

336

337

338

339

340

341

RPE cells. It appears that 5-AZA-dC may have therapeutic value in the treatment of PVR.

However, the mechanisms underlying the blockade of $\alpha$-SMA and FN expression are complex, and further investigation is warranted.

Recently, the role of histone modifications associated with EMT has been assessed in RPE cells. However, there has been little research into the regulation of RPE cell EMT by histone modification. Boles et al. (2020) reported that TGF- $\beta 1$ and TNF-a co-treatment (TNT) induces an EMT program in adult human RPE stem cell (RPESC)-RPE cells, involving an apparent reorganization of $\mathrm{H} 3 \mathrm{~K} 27 \mathrm{ac}$ and $\mathrm{H} 3 \mathrm{~K} 4 \mathrm{me} 1$ patterns at distal enhancers. The regions that gain $\mathrm{H} 3 \mathrm{~K} 27 \mathrm{ac}$ tend to have a high $\mathrm{H} 3 \mathrm{~K} 4 \mathrm{me} 1 / \mathrm{H} 3 \mathrm{~K} 4 \mathrm{me} 3$ ratio, indicating that they have enhancer activity and are associated with upregulated genes. Xiao et al. (2014) found that the expression of histone deacetylases (HDACs) in TGF- $\beta$-induced EMT of RPE cells was increased, and that Trichostatin A (TSA), a class I and II HDAC inhibitor, attenuated TGF- $\beta 2$-induced EMT by inhibiting the canonical SMAD pathway and the non-canonical signaling pathways, including Akt, p38MAPK, ERK1/2 pathways and Notch pathway. Therefore, histone modifications may participate in the regulation of RPE cell EMT, and HDAC inhibitors may have potential as drugs for the prevention and treatment of PVR.

The study of EMT mechanisms at the RNA level has provided new perspectives on the treatment of PVR (Kaneko \& Terasaki 2017; Wang et al. 2016). MicroRNAs (miRNAs) are small noncoding RNAs that contribute to cellular processes by regulating gene expression. In differentiated RPE cells, microRNA-204 is highly expressed, and represses the expression of

type II TGF- $\beta$ receptors and Snail 2, maintaining epithelial structure and function. In contrast, low expression levels of miR-204 and anti-miR-204 promote RPE cells proliferation, participating in EMT (Wang et al. 2010). MicroRNA-194 overexpression can also suppress RPE cell EMT by attenuating the expression of Zeb1 (Cui et al. 2019). In addition to miRNAs, long non-coding RNAs (lncRNAs) contribute to the regulation of RPE EMT (Zhang et al. 2019). In RPE cells treated with PVR vitreous or TGF- $\beta 1$, MALAT1 expression is increased, and knockdown of MALAT1 attenuates the phosphorylation of SMAD2/3 and the expression of Snail, Slug, and Zeb1, preventing cell migration and proliferation (Yang et al. 2016). In patients with PVR, MALAT1 is increased in the blood, and is reduced after surgery. Thus, MALAT1 may be a potential prognostic and diagnostic indicator for PVR (Zhou et al. 2015). 3.4 Signaling Pathways of EMT

During RPE cell EMT, extracellular signals change the expression of genes encoding epithelial and mesenchymal proteins and mediate cellular behavior such as cell migration, proliferation, and apoptosis through a network of interacting signaling pathways that contribute to the development of PVR (Chen et al. 2014a; Chen et al. 2014b; Lee-Rivera et al. 2015). 
342

343

344

345

346

347

348

349

350

351

352

353

354

355

356

357

358

359

360

361

362

363

364

365

366

367

368

369

370

371

372

373

374

375

Among these, transforming growth factor- $\beta$ (TGF- $\beta$ ) and its intracellular cascades play a key role in the EMT of RPE cells.

TGF- $\beta$ induces EMT of RPE cells via two pathways: the classical SMAD-dependent pathway and the SMAD-independent pathway (Fig 2) (Cai et al. 2018; He et al. 2017; Heffer et al. 2019; Ishikawa et al. 2015; Takahashi et al. 2015; Yao et al. 2019; Zhang et al. 2017; Zhang et al. 2018b; Zhou et al. 2017). In the SMAD dependent pathway, TGF- $\beta$ binds to cell surface receptor complexes, and activates type I TGF- $\beta$ receptors, which phosphorylate SMAD2 and SMAD3. The activated SMADs combine with SMAD4 to form a SMAD complex, which then enters the nucleus and combines with regulatory elements to regulate the expression of key genes associated with EMT. In addition to SMAD-dependent signaling, TGF $\beta$ induces EMT through SMAD independent signaling pathways including Rho GTPase-dependent pathways (Lee et al. 2008), PI3K/Akt pathway (Huang et al. 2017; Yokoyama et al. 2012), mitogen-activated kinase (MAPK) pathways (Chen et al. 2017; Lee et al. 2020; Matoba et al. 2017; Schiff et al. 2019) and Jagged/Notch signaling pathway (Zhang et al. 2017). The MAPK signaling pathways include extracellular signal-regulated kinase(ERK) MAPK pathway, p38 MAPK pathway, and JUN Nterminal kinase (JNK) pathway (Parrales et al. 2013; Schiff et al. 2019; Xiao et al. 2014; Zhang et al. 2018a).

The Rho pathway has been reported to regulate the assembly and organization of the actin cytoskeleton and associated gene expression, and may be essential for the fibrotic response of RPE cells in PVR. In TGF- $\beta 1$-treated ARPE-19 cells, activated RhoA or its downstream effector Rho kinase (ROCK) increase the kinase activity of LIM kinase (LIMK) which then phosphorylates cofilin. This phosphorylation attenuates the activity of cofilin, which promotes actin polymerization and reorganizes the actin cytoskeleton, leading to stress fiber formation (Lee et al. 2008). TGF- $\beta$-induced RhoA activation also facilitates cell migration and increases $\alpha$ SMA expression in primary RPE cells (Tsapara et al. 2010). Itoh et al. (2007) demonstrated that

ROCK inhibitor Y27632 and RhoA inhibitor, simvastatin, suppress TGF- $\beta 2$-induced type I collagen expression in ARPE-19 cells, and confirmed the existence of crosstalk between the SMAD pathway and the Rho pathway. Some studies have suggested that activated SMAD3 induces NET1 gene expression to regulate RhoA activation in RPE cells (Lee et al. 2010). Moreover, thrombin can activate Rho and ROCK, leading to myosin light chain (MLC) phosphorylation and actin stress fiber formation in EMT of RPE cells (Fig 3)(Ruiz-Loredo et al. 2011). Therefore, ROCK inhibitor and RhoA inhibitor may be new potential therapeutic target drugs for PVR.

The PI3K/Akt pathway mediates a broad range of cellular functions, such as cell 
376

377

378

379

380

381

382

383

384

385

386

387

388

389

390

391

392

393

394

395

396

397

398

399

400

401

402

403

404

405

406

407

408

409

410

411

transformation, migration, proliferation, apoptosis, and gene expression (Aguilar-Solis et al. 2017; Liu et al. 2019). During PVR, binding of TGF- $\beta$ to its receptor activates PI3K, resulting in the phosphorylation of Akt; activated Akt inhibits glycogen synthase kinase $3 \beta$ (GSK-3 $\beta$ ), promoting EMT in RPE cells (Shukal et al. 2020; Zhang et al. 2018a). Researchers have found that inhibition or knockdown of GSK-3 $\beta$ promotes cell migration and collagen contraction in ARPE-19 cells, while GSK-3 $\beta$ overexpression and PI3K/Akt inhibitor reverse these cellular responses (Huang et al. 2017). Some studies have shown that thrombin can activate PI3K, resulting in increased cyclin D1 expression and RPE cell proliferation, processes that are involved in the development of PVR through PDK1/Akt and PKC $\zeta /$ mTORC signaling (Fig 3) (Lee-Rivera et al. 2015; Palma-Nicolás \& López-Colomé 2013; Parrales et al. 2013).

In addition to the PI3K-AKT pathway, other kinase pathways contribute to EMT in cooperation with the SMAD-dependent signaling pathways. In human RPE cells, TGF- $\beta$ activates TGF- $\beta$-activated kinase 1 (TAK1), which subsequently transduces signals to several downstream effectors, including p38 (Heffer et al. 2019), JNK (Kimura et al. 2015) and nuclear factor- $\kappa \mathrm{B}(\mathrm{NF}-\kappa \mathrm{B})$ (Chen et al. 2016b), which participate in EMT. Dvashi et al. (2015) found that TAK1 inhibitor caused a reduction in both $\mathrm{p} 38$ and SMAD2/3 activity, attenuating cell migration, cell contractility and $\alpha$-SMA expression in TGF- $\beta 1$-induced RPE cells. Moreover, the ERK MAPK pathway plays a role in TGF- $\beta$-induced EMT and cooperates with other signaling pathways in the regulation of EMT in RPE cells. Recent studies (Chen et al. 2014b; Tan et al. 2017; Xiao et al. 2014) have shown that blocking the ERK1/2 pathway inhibits the phosphorylation of SMAD2 and the Jagged/Notch pathway. Inhibition of the Jagged/Notch signaling pathway can alleviate TGF- $\beta 2$-induced EMT by regulating the expression of Snail, Slug and Zeb1 (Fig 3); this also suppresses the ERK1/2 signaling (Chen et al. 2014b).

The contribution of growth factors other than TGF- $\beta$, such as HGF, fibroblast growth factor (FGF), epidermal growth factor (EGF) and platelet derived growth factor (PDGF) should also be factored in with regard to the induction of RPE EMT. These factors bind to and stimulate the autophosphorylation of transmembrane receptors on Tyr, subsequently participating in RPE cell EMT via PI3K/Akt pathway, ERK MAPK pathway, p38 MAPK pathway (Fig 3) (Chen et al. 2016a; Ozal et al. 2020).Chen et al. (2012) explored the role of $\mathrm{Wnt} / \beta$-catenin signaling in PVR, and found that when EGTA disrupted contact inhibition in RPE cells, EGF+FGF2 could activate Wnt signaling and increase nuclear levels of $\beta$-catenin, which interacts with TCF and/or LEF, leading to cell proliferation (Fig 3); and EGF+FGF2 cooperated with TGF- $\beta 1$ to induce EMT through SMAD/Zeb1/2 signaling. Acting together, various inductive signals received by RPE cells from their niche can trigger the activation of EMT programs by individual intracellular cascades or the crosstalk of multiple intracellular signaling pathways.

3.5 Interventions of RPE EMT 
412

413

414

415

416

417

418

419

420

421

422

423

424

425

426

427

428

429

430

431

432

433

434

435

436

437

438

439

440

441

442

443

444

445

446

Therapeutic interventions against RPE EMT have largely been explored in mechanistic experiments using in vitro cell culture and in vivo animal models. To date, some promising drug candidates have been trialed in preclinical studies of PVR, including TGF- $\beta$ receptor inhibitors, peroxisome proliferator-activated receptor (PPAR)- $\gamma$ agonists, retinoic acid receptor- $\gamma$ (RAR- $\gamma$ ) agonists and methotrexate (Shu et al. 2020; Zhou et al. 2020).Nassar et al. (2014) found that TGF- $\beta$ receptor 1 inhibitor LY-364947 (LY) attenuates RPE cell transdifferentiation in vitro, and that intravitreal injection of LY completely prevents PVR and TRD in vivo. Evidence is emerging to show that the up-regulation of PPAR- $\gamma$ expression may be beneficial for the treatment of fibrosis in several organs(Wang et al. 2019). Hatanaka et al. (2012) reported that PPAR- $\gamma$ agonist pioglitazone could prevent TGF- $\beta$-induced morphological changes and the upregulation of EMT-related markers in primary monkey RPE cells, through inhibition of the SMAD pathway. Some drugs, including dichloroacetate (DCA)(Shukal et al. 2020), salinomycin (SNC)(Heffer et al. 2019), resveratrol(Ishikawa et al. 2015), protein kinase A inhibitor H89 (Lyu et al. 2020) and heavy chain-hyaluronan/pentraxin3(He et al. 2017), reportedly inhibit EMT in an in vitro EMT cell model and prevent PVR development by blocking the activation of theTGF- $\beta$ pathway. Thus, inhibition of EMT by pharmacological agents may be an effective strategy to prevent PVR development.

\section{Conclusion}

Clinical and experimental studies have shown that RPE cells play an important role in PVR. Junctional complexes are crucial for the maintenance of RPE polarity. Under the influence of growth factors and cytokines, RPE cells lose cell-cell contact and apical-basal polarity, and undergo EMT via multiple signaling pathways, which promote cell proliferation, migration, and ECM production. RPE cells further transform into myofibroblasts and form fibrocellular membranes that have contractile activity and strain the retina, leading to tractional retinal detachment in PVR. As a complex refractory blinding disorder, PVR involves multiple signaling pathways and factors. In addition, the specialized polarity of RPE cells is fundamental for retinal homeostasis, and RPE EMT plays a key role in the development of PVR. Nevertheless, further research into the mechanisms underlying RPE polarity and EMT is needed to prevent this devastating complication. A deeper understanding of RPE polarization is fundamental for elucidating the mechanism of EMT initiation and progression, and is essential to exploring the potential pharmacologic prophylactic and therapeutic approaches to PVR. Various factors, such as microenvironmental signals, transcription factors, and epigenetic factors, participate in the regulation of EMT at different molecular levels. Further studies about the detailed molecular mechanisms of EMT are needed to facilitate the development of therapeutic strategies for PVR.

\section{References}


Aberle H, Butz S, Stappert J, Weissig H, Kemler R, and Hoschuetzky H. 1994. Assembly of the cadherin-catenin complex in vitro with recombinant proteins. J Cell Sci 107 ( Pt 12):3655-3663.

Aguilar-Solis ED, Lee-Rivera I, Álvarez-Arce A, López E, and López-Colomé AM. 2017. FAK phosphorylation plays a central role in thrombin-induced RPE cell migration. Cell Signal 36:56-66. 10.1016/j.cellsig.2017.04.016

Amarnani D, Machuca-Parra Al, Wong LL, Marko CK, Stefater JA, Stryjewski TP, Eliott D, Arboleda-Velasquez JF, and Kim LA. 2017. Effect of Methotrexate on an In Vitro Patient-Derived Model of Proliferative Vitreoretinopathy. Invest Ophthalmol Vis Sci 58:3940-3949. 10.1167/iovs.16-20912

Balda MS, Flores-Maldonado C, Cereijido M, and Matter K. 2000. Multiple domains of occludin are involved in the regulation of paracellular permeability. J Cell Biochem 78:85-96.

Balda MS, Garrett MD, and Matter K. 2003. The ZO-1-associated Y-box factor ZONAB regulates epithelial cell proliferation and cell density. J Cell Biol 160:423-432. 10.1083/jcb.200210020

Balda MS, and Matter K. 2016. Tight junctions as regulators of tissue remodelling. Curr Opin Cell Biol 42:94-101. 10.1016/j.ceb.2016.05.006

Bao H, Yang S, Li H, Yao H, Zhang Y, Zhang J, Xu G, Jin H, and Wang F. 2019. The Interplay Between E-Cadherin, Connexin 43, and Zona Occludens 1 in Retinal Pigment Epithelial Cells. Invest Ophthalmol Vis Sci 60:51045111. 10.1167/iovs.19-27768

Bastiaans J, Mulder VC, van Meurs JC, Smits-Te Nijenhuis M, van Holten-Neelen C, van Hagen PM, and Dik WA. 2018. Dabigatran inhibits intravitreal thrombin activity. Acta Ophthalmol 96:452-458. 10.1111/aos.13630

Bazzoni G, and Dejana E. 2004. Endothelial cell-to-cell junctions: molecular organization and role in vascular homeostasis. Physiol Rev 84:869-901. 10.1152/physrev.00035.2003

Bazzoni G, Martinez-Estrada OM, Orsenigo F, Cordenonsi M, Citi S, and Dejana E. 2000. Interaction of junctional adhesion molecule with the tight junction components ZO-1, cingulin, and occludin. J Biol Chem 275:2052020526. 10.1074/jbc.M905251199

Benedicto I, Lehmann GL, Ginsberg M, Nolan DJ, Bareja R, Elemento O, Salfati Z, Alam NM, Prusky GT, Llanos P, Rabbany SY, Maminishkis A, Miller SS, Rafii S, and Rodriguez-Boulan E. 2017. Concerted regulation of retinal pigment epithelium basement membrane and barrier function by angiocrine factors. Nat Commun 8:15374. 10.1038/ncomms15374

Bhat AA, Uppada S, Achkar IW, Hashem S, Yadav SK, Shanmugakonar M, Al-Naemi HA, Haris M, and Uddin S. 2018. Tight Junction Proteins and Signaling Pathways in Cancer and Inflammation: A Functional Crosstalk. Front Physiol 9:1942. 10.3389/fphys.2018.01942

Boles NC, Fernandes M, Swigut T, Srinivasan R, Schiff L, Rada-Iglesias A, Wang Q, Saini JS, Kiehl T, Stern JH, Wysocka J, Blenkinsop TA, and Temple S. 2020. Epigenomic and Transcriptomic Changes During Human RPE EMT in a Stem Cell Model of Epiretinal Membrane Pathogenesis and Prevention by Nicotinamide. Stem Cell Reports 14:631-647. 10.1016/j.stemcr.2020.03.009

Bonnans C, Chou J, and Werb Z. 2014. Remodelling the extracellular matrix in development and disease. Nat Rev Mol Cell Biol 15:786-801. 10.1038/nrm3904

Bulloj A, Maminishkis A, Mizui M, and Finnemann SC. 2018. Semaphorin4D-PlexinB1 Signaling Attenuates Photoreceptor Outer Segment Phagocytosis by Reducing Rac1 Activity of RPE Cells. Mol Neurobiol 55:43204332. 10.1007/s12035-017-0649-5

Caceres PS, Benedicto I, Lehmann GL, and Rodriguez-Boulan EJ. 2017. Directional Fluid Transport across Organ-Blood Barriers: Physiology and Cell Biology. Cold Spring Harb Perspect Biol 9. 10.1101/cshperspect.a027847

Peer] reviewing PDF | (2020:06:49749:2:0:NEW 15 Sep 2020) 
488

489

490

491

492

493

494

495

496

497

498

499

500

501

502

503

504

505

506

507

508

509

510

511

512

513

514

515

516

517

518

519

520

521

522

523

524

525

526

527

528

Caceres PS, and Rodriguez-Boulan E. 2020. Retinal pigment epithelium polarity in health and blinding diseases. Curr Opin Cell Biol 62:37-45. 10.1016/j.ceb.2019.08.001

Cai W, Yu D, Fan J, Liang X, Jin H, Liu C, Zhu M, Shen T, Zhang R, Hu W, Wei Q, and Yu J. 2018. Quercetin inhibits transforming growth factor $\beta$ 1-induced epithelial-mesenchymal transition in human retinal pigment epithelial cells via the Smad pathway. Drug Des Devel Ther 12:4149-4161. 10.2147/dddt.s185618

Campbell HK, Maiers JL, and DeMali KA. 2017. Interplay between tight junctions \& adherens junctions. Exp Cell Res 358:39-44. 10.1016/j.yexcr.2017.03.061

Charteris DG. 1998. Growth factors in proliferative vitreoretinopathy. Br J Ophthalmol 82:106. 10.1136/bjo.82.2.106

Chen HC, Zhu YT, Chen SY, and Tseng SC. 2012. Wnt signaling induces epithelial-mesenchymal transition with proliferation in ARPE-19 cells upon loss of contact inhibition. Lab Invest 92:676-687. 10.1038/labinvest.2011.201

Chen X, Tzekov R, Su M, Hong H, Min W, Han A, and Li W. 2016a. Auranofin Inhibits Retinal Pigment Epithelium Cell Survival through Reactive Oxygen Species-Dependent Epidermal Growth Factor Receptor/ MitogenActivated Protein Kinase Signaling Pathway. PLoS One 11:e0166386. 10.1371/journal.pone.0166386

Chen X, Xiao W, Liu X, Zeng M, Luo L, Wu M, Ye S, and Liu Y. 2014a. Blockade of Jagged/Notch pathway abrogates transforming growth factor $\beta$ 2-induced epithelial-mesenchymal transition in human retinal pigment epithelium cells. Curr Mol Med 14:523-534. 10.2174/1566524014666140331230411

Chen X, Xiao W, Wang W, Luo L, Ye S, and Liu Y. 2014b. The complex interplay between ERK1/2, TGF $\beta$ /Smad, and Jagged/Notch signaling pathways in the regulation of epithelial-mesenchymal transition in retinal pigment epithelium cells. PLoS One 9:e96365. 10.1371/journal.pone.0096365

Chen Z, Mei Y, Lei H, Tian R, Ni N, Han F, Gan S, and Sun S. 2016b. LYTAK1, a TAK1 inhibitor, suppresses proliferation and epithelial-mesenchymal transition in retinal pigment epithelium cells. Mol Med Rep 14:145-150. 10.3892/mmr.2016.5275

Chen Z, Ni N, Mei Y, and Yang Z. 2017. LYTAK1 attenuates proliferation of retinal pigment epithelial cells through TGF- $\beta$-mediated epithelial-mesenchymal transition via the ERK/AKT signaling pathway. Exp Ther Med 14:4951-4957. 10.3892/etm.2017.5187

Chen Z, Shao Y, and Li X. 2015. The roles of signaling pathways in epithelial-to-mesenchymal transition of PVR. Mol Vis 21:706-710.

Chiba C. 2014. The retinal pigment epithelium: an important player of retinal disorders and regeneration. Exp Eye Res 123:107-114. 10.1016/j.exer.2013.07.009

Coffee RE, Jiang L, and Rahman SA. 2014. Proliferative vitreoretinopathy: advances in surgical management. Int Ophthalmol Clin 54:91-109. 10.1097/iio.0000000000000023

Committee TRST. 1983. The classification of retinal detachment with proliferative vitreoretinopathy. Ophthalmology 90:121-125. 10.1016/s0161-6420(83)34588-7

Craig VJ, Zhang L, Hagood JS, and Owen CA. 2015. Matrix metalloproteinases as therapeutic targets for idiopathic pulmonary fibrosis. Am J Respir Cell Mol Biol 53:585-600. 10.1165/rcmb.2015-0020TR

Cui L, Lyu Y, Jin X, Wang Y, Li X, Wang J, Zhang J, Deng Z, Yang N, Zheng Z, Guo Y, Wang C, Mao R, Xu J, Gao F, Jin C, Zhang J, Tian H, Xu GT, and Lu L. 2019. miR-194 suppresses epithelial-mesenchymal transition of retinal pigment epithelial cells by directly targeting ZEB1. Ann Transl Med 7:751. 10.21037/atm.2019.11.90

Deora AA, Philp N, Hu J, Bok D, and Rodriguez-Boulan E. 2005. Mechanisms regulating tissue-specific polarity of monocarboxylate transporters and their chaperone CD147 in kidney and retinal epithelia. Proc Natl Acad

Peer] reviewing PDF | (2020:06:49749:2:0:NEW 15 Sep 2020) 
Sci U S A 102:16245-16250. 10.1073/pnas.0504419102

Ding X, Bai Y, Zhu X, Li T, Jin E, Huang L, Yu W, and Zhao M. 2017. The effects of pleiotrophin in proliferative vitreoretinopathy. Graefes Arch Clin Exp Ophthalmol 255:873-884. 10.1007/s00417-016-3582-9

Dongre A, and Weinberg RA. 2019. New insights into the mechanisms of epithelial-mesenchymal transition and implications for cancer. Nat Rev Mol Cell Biol 20:69-84. 10.1038/s41580-018-0080-4

Dvashi Z, Goldberg M, Adir O, Shapira M, and Pollack A. 2015. TGF- $\beta 1$ induced transdifferentiation of rpe cells is mediated by TAK1. PLoS One 10:e0122229. 10.1371/journal.pone.0122229

Eastlake K, Banerjee PJ, Angbohang A, Charteris DG, Khaw PT, and Limb GA. 2016. Müller glia as an important source of cytokines and inflammatory factors present in the gliotic retina during proliferative vitreoretinopathy. Glia 64:495-506. 10.1002/glia.22942

Feist RM, Jr., King JL, Morris R, Witherspoon CD, and Guidry C. 2014. Myofibroblast and extracellular matrix origins in proliferative vitreoretinopathy. Graefes Arch Clin Exp Ophthalmol 252:347-357. 10.1007/s00417-0132531-0

Feng H, Zhao X, Guo Q, Feng Y, Ma M, Guo W, Dong X, Deng C, Li C, Song X, Han S, and Cao L. 2019. Autophagy resists EMT process to maintain retinal pigment epithelium homeostasis. Int J Biol Sci 15:507-521. 10.7150/ijbs.30575

Ferrington DA, Sinha D, and Kaarniranta K. 2016. Defects in retinal pigment epithelial cell proteolysis and the pathology associated with age-related macular degeneration. Prog Retin Eye Res 51:69-89. 10.1016/j.preteyeres.2015.09.002

Fields MA, Del Priore LV, Adelman RA, and Rizzolo LJ. 2019. Interactions of the choroid, Bruch's membrane, retinal pigment epithelium, and neurosensory retina collaborate to form the outer blood-retinal-barrier. Prog Retin Eye Res:100803. 10.1016/j.preteyeres.2019.100803

Furuse M, Itoh M, Hirase T, Nagafuchi A, Yonemura S, Tsukita S, and Tsukita S. 1994. Direct association of occludin with ZO-1 and its possible involvement in the localization of occludin at tight junctions. J Cell Biol 127:16171626. 10.1083/jcb.127.6.1617

Furuse M, Sasaki H, Fujimoto K, and Tsukita S. 1998. A single gene product, claudin-1 or -2 , reconstitutes tight junction strands and recruits occludin in fibroblasts. The Journal of cell biology 143:391-401. 10.1083/jcb.143.2.391

Gamulescu MA, Chen Y, He S, Spee C, Jin M, Ryan SJ, and Hinton DR. 2006. Transforming growth factor beta2-induced myofibroblastic differentiation of human retinal pigment epithelial cells: regulation by extracellular matrix proteins and hepatocyte growth factor. Exp Eye Res 83:212-222. 10.1016/j.exer.2005.12.007

Garweg JG, Tappeiner C, and Halberstadt M. 2013. Pathophysiology of proliferative vitreoretinopathy in retinal detachment. Surv Ophthalmol 58:321-329. 10.1016/j.survophthal.2012.12.004

Georgiadis A, Tschernutter M, Bainbridge JW, Balaggan KS, Mowat F, West EL, Munro PM, Thrasher AJ, Matter K, Balda MS, and Ali RR. 2010. The tight junction associated signalling proteins ZO-1 and ZONAB regulate retinal pigment epithelium homeostasis in mice. PLoS One 5:e15730. 10.1371/journal.pone.0015730

González-Mariscal L, Domínguez-Calderón A, Raya-Sandino A, Ortega-Olvera JM, Vargas-Sierra O, and MartínezRevollar G. 2014. Tight junctions and the regulation of gene expression. Semin Cell Dev Biol 36:213-223. 10.1016/j.semcdb.2014.08.009

Gonzalez DM, and Medici D. 2014. Signaling mechanisms of the epithelial-mesenchymal transition. Sci Signal 7:re8. 10.1126/scisignal.2005189 
Greene WA, Burke TA, Kaini RR, Por ED, and Wang HC. 2017. Polarized Secretion of Matrix Metalloproteinases and Their Inhibitors by Retinal Pigment Epithelium Derived from Induced Pluripotent Stem Cells During Wound Healing. J Ocul Pharmacol Ther 33:132-140. 10.1089/jop.2016.0070

Guettler S, Vartiainen MK, Miralles F, Larijani B, and Treisman R. 2008. RPEL motifs link the serum response factor cofactor MAL but not myocardin to Rho signaling via actin binding. Mol Cell Biol 28:732-742. 10.1128/mcb.01623-07

Günzel D, and Yu AS. 2013. Claudins and the modulation of tight junction permeability. Physiol Rev 93:525-569. 10.1152/physrev.00019.2012

Harada C, Mitamura Y, and Harada T. 2006. The role of cytokines and trophic factors in epiretinal membranes: involvement of signal transduction in glial cells. Prog Retin Eye Res 25:149-164. 10.1016/j.preteyeres.2005.09.001

Hatanaka H, Koizumi N, Okumura N, Kay EP, Mizuhara E, Hamuro J, and Kinoshita S. 2012. Epithelial-mesenchymal transition-like phenotypic changes of retinal pigment epithelium induced by TGF- $\beta$ are prevented by PPAR$\gamma$ agonists. Invest Ophthalmol Vis Sci 53:6955-6963. 10.1167/iovs.12-10488

Hazim RA, Volland S, Yen A, Burgess BL, and Williams DS. 2019. Rapid differentiation of the human RPE cell line, ARPE-19, induced by nicotinamide. Exp Eye Res 179:18-24. 10.1016/j.exer.2018.10.009

He H, Kuriyan AE, Su CW, Mahabole M, Zhang Y, Zhu YT, Flynn HW, Parel JM, and Tseng SC. 2017. Inhibition of Proliferation and Epithelial Mesenchymal Transition in Retinal Pigment Epithelial Cells by Heavy ChainHyaluronan/Pentraxin 3. Sci Rep 7:43736. 10.1038/srep43736

He S, Barron E, Ishikawa K, Nazari Khanamiri H, Spee C, Zhou P, Kase S, Wang Z, Dustin LD, and Hinton DR. 2015. Inhibition of DNA Methylation and Methyl-CpG-Binding Protein 2 Suppresses RPE Transdifferentiation: Relevance to Proliferative Vitreoretinopathy. Invest Ophthalmol Vis Sci 56:5579-5589. 10.1167/iovs.1416258

Heffer AM, Proaño J, Roztocil E, Phipps RP, Feldon SE, Huxlin KR, Sime PJ, Libby RT, Woeller CF, and Kuriyan AE. 2019. The polyether ionophore salinomycin targets multiple cellular pathways to block proliferative vitreoretinopathy pathology. PLoS One 14:e0222596. 10.1371/journal.pone.0222596

Hinz B, Celetta G, Tomasek JJ, Gabbiani G, and Chaponnier C. 2001. Alpha-smooth muscle actin expression upregulates fibroblast contractile activity. Mol Biol Cell 12:2730-2741. 10.1091/mbc.12.9.2730

Hiscott P, Morino I, Alexander R, Grierson I, and Gregor Z. 1989. Cellular components of subretinal membranes in proliferative vitreoretinopathy. Eye (Lond) 3 ( Pt 5):606-610. 10.1038/eye.1989.94

Huang L, Zhang C, Su L, and Song Z. 2017. GSK3 $\beta$ attenuates TGF- $\beta 1$ induced epithelial-mesenchymal transition and metabolic alterations in ARPE-19 cells. Biochem Biophys Res Commun 486:744-751. 10.1016/j.bbrc.2017.03.113

Idrees S, Sridhar J, and Kuriyan AE. 2019. Proliferative Vitreoretinopathy: A Review. Int Ophthalmol Clin 59:221-240. 10.1097/iio.0000000000000258

Ishikawa K, He S, Terasaki H, Nazari H, Zhang H, Spee C, Kannan R, and Hinton DR. 2015. Resveratrol inhibits epithelial-mesenchymal transition of retinal pigment epithelium and development of proliferative vitreoretinopathy. Sci Rep 5:16386. 10.1038/srep16386

Islas S, Vega J, Ponce L, and González-Mariscal L. 2002. Nuclear localization of the tight junction protein ZO-2 in epithelial cells. Exp Cell Res 274:138-148. 10.1006/excr.2001.5457

Itoh Y, Kimoto K, Imaizumi M, and Nakatsuka K. 2007. Inhibition of RhoA/Rho-kinase pathway suppresses the

Peer) reviewing PDF | (2020:06:49749:2:0:NEW 15 Sep 2020) 
611

612

613

614

615

616

617

618

619

620

621

622

623

624

625

626

627

628

629

630

631

632

633

634

635

636

637

638

639

640

641

642

643

644

645

646

647

648

649

650

651 expression of type I collagen induced by TGF-beta2 in human retinal pigment epithelial cells. Exp Eye Res 84:464-472. 10.1016/j.exer.2006.10.017

Jin M, Barron E, He S, Ryan SJ, and Hinton DR. 2002. Regulation of RPE intercellular junction integrity and function by hepatocyte growth factor. Invest Ophthalmol Vis Sci 43:2782-2790.

Jin M, Chen Y, He S, Ryan SJ, and Hinton DR. 2004. Hepatocyte growth factor and its role in the pathogenesis of retinal detachment. Invest Ophthalmol Vis Sci 45:323-329. 10.1167/iovs.03-0355

Jin Y, Chen H, Xu X, Hu Y, Wang C, and Ma Z. 2017. TRAUMATIC PROLIFERATIVE VITREORETINOPATHY: Clinical and Histopathological Observations. Retina 37:1236-1245. 10.1097/iae.0000000000001350

Kadler KE, Hill A, and Canty-Laird EG. 2008. Collagen fibrillogenesis: fibronectin, integrins, and minor collagens as organizers and nucleators. Curr Opin Cell Biol 20:495-501. 10.1016/j.ceb.2008.06.008

Kalluri R, and Weinberg RA. 2009. The basics of epithelial-mesenchymal transition. J Clin Invest 119:1420-1428. $10.1172 /$ jci39104

Kaneko H, and Terasaki H. 2017. Biological Involvement of MicroRNAs in Proliferative Vitreoretinopathy. Trans/ Vis Sci Technol 6:5. 10.1167/tvst.6.4.5

Khan MA, Brady CJ, and Kaiser RS. 2015. Clinical management of proliferative vitreoretinopathy: an update. Retina 35:165-175. 10.1097/iae.0000000000000447

Khankan R, Oliver N, He S, Ryan SJ, and Hinton DR. 2011. Regulation of fibronectin-EDA through CTGF domain-specific interactions with TGF $\beta 2$ and its receptor TGF $\beta$ RII. Invest Ophthalmol Vis Sci 52:5068-5078. 10.1167/iovs.11-7191

Khristov V, Wan Q, Sharma R, Lotfi M, Maminishkis A, and Bharti K. 2018. Polarized Human Retinal Pigment Epithelium Exhibits Distinct Surface Proteome on Apical and Basal Plasma Membranes. Methods Mol Biol 1722:223-247. 10.1007/978-1-4939-7553-2_15

Kimura K, Orita T, Liu Y, Yang Y, Tokuda K, Kurakazu T, Noda T, Yanai R, Morishige N, Takeda A, Ishibashi T, and Sonoda KH. 2015. Attenuation of EMT in RPE cells and subretinal fibrosis by an RAR- $\gamma$ agonist. J Mol Med (Berl) 93:749-758. 10.1007/s00109-015-1289-8

Lamouille S, Xu J, and Derynck R. 2014. Molecular mechanisms of epithelial-mesenchymal transition. Nat Rev Mol Cell Biol 15:178-196. 10.1038/nrm3758

Lee-Rivera I, López E, Parrales A, Alvarez-Arce A, and López-Colomé AM. 2015. Thrombin promotes the expression of Ccnd1 gene in RPE cells through the activation of converging signaling pathways. Exp Eye Res 139:81-89. 10.1016/j.exer.2015.08.001

Lee H, Hwang-Bo H, Ji SY, Kim MY, Kim SY, Park C, Hong SH, Kim GY, Song KS, Hyun JW, and Choi YH. 2020. Diesel particulate matter2.5 promotes epithelial-mesenchymal transition of human retinal pigment epithelial cells via generation of reactive oxygen species. Environ Pollut 262:114301. 10.1016/j.envpol.2020.114301

Lee J, Ko M, and Joo CK. 2008. Rho plays a key role in TGF-beta1-induced cytoskeletal rearrangement in human retinal pigment epithelium. J Cell Physiol 216:520-526. 10.1002/jcp.21424

Lee J, Moon HJ, Lee JM, and Joo CK. 2010. Smad3 regulates Rho signaling via NET1 in the transforming growth factorbeta-induced epithelial-mesenchymal transition of human retinal pigment epithelial cells. J Biol Chem 285:26618-26627. 10.1074/jbc.M109.073155

Lehmann GL, Benedicto I, Philp NJ, and Rodriguez-Boulan E. 2014. Plasma membrane protein polarity and trafficking in RPE cells: past, present and future. Exp Eye Res 126:5-15. 10.1016/j.exer.2014.04.021

Li D, Yuan D, Shen H, Mao X, Yuan S, and Liu Q. 2019. Gremlin-1: An endogenous BMP antagonist induces epithelial-

Peer) reviewing PDF | (2020:06:49749:2:0:NEW 15 Sep 2020) 
652

653

654

655

656

657

658

659

660

661

662

663

664

665

666

667

668

669

670

671

672

673

674

675

676

677

678

679

680

681

682

683

684

685

686

687

688

689

690

691

692

mesenchymal transition and interferes with redifferentiation in fetal RPE cells with repeated wounds. Mol Vis 25:625-635.

Li H, Li M, Xu D, Zhao C, Liu G, and Wang F. 2014. Overexpression of Snail in retinal pigment epithelial triggered epithelial-mesenchymal transition. Biochem Biophys Res Commun 446:347-351. 10.1016/j.bbrc.2014.02.119

Li X, Zhao M, and He S. 2020. RPE epithelial-mesenchymal transition plays a critical role in the pathogenesis of proliferative vitreoretinopathy. Ann Transl Med 8:263. 10.21037/atm.2020.03.86

Lidgerwood GE, Morris AJ, Conquest A, Daniszewski M, Rooney LA, Lim SY, Hernández D, Liang HH, Allen P, Connell PP, Guymer RH, Hewitt AW, and Pébay A. 2018. Role of lysophosphatidic acid in the retinal pigment epithelium and photoreceptors. Biochim Biophys Acta Mol Cell Biol Lipids 1863:750-761. 10.1016/j.bbalip.2018.04.007

Lilien J, and Balsamo J. 2005. The regulation of cadherin-mediated adhesion by tyrosine phosphorylation/dephosphorylation of beta-catenin. Curr Opin Cell Biol 17:459-465. 10.1016/j.ceb.2005.08.009

Limb GA, Little BC, Meager A, Ogilvie JA, Wolstencroft RA, Franks WA, Chignell AH, and Dumonde DC. 1991. Cytokines in proliferative vitreoretinopathy. Eye (Lond) 5 ( Pt 6):686-693. 10.1038/eye.1991.126

Lindsey ML, lyer RP, Jung M, DeLeon-Pennell KY, and Ma Y. 2016. Matrix metalloproteinases as input and output signals for post-myocardial infarction remodeling. I Mol Cell Cardiol 91:134-140. 10.1016/j.yjmcc.2015.12.018

Liou GI, Matragoon S, Samuel S, Behzadian MA, Tsai NT, Gu X, Roon P, Hunt DM, Hunt RC, Caldwell RB, and Marcus DM. 2002. MAP kinase and beta-catenin signaling in HGF induced RPE migration. Mol Vis 8:483-493.

Liu L, Wu N, Wang Y, Zhang X, Xia B, Tang J, Cai J, Zhao Z, Liao Q, and Wang J. 2019. TRPM7 promotes the epithelialmesenchymal transition in ovarian cancer through the calcium-related PI3K / AKT oncogenic signaling. J Exp Clin Cancer Res 38:106. 10.1186/s13046-019-1061-y

Liu Y, Ye F, Li Q, Tamiya S, Darling DS, Kaplan HJ, and Dean DC. 2009. Zeb1 represses Mitf and regulates pigment synthesis, cell proliferation, and epithelial morphology. Invest Ophthalmol Vis Sci 50:5080-5088. 10.1167/iovs.08-2911

Lutty GA, and McLeod DS. 2018. Development of the hyaloid, choroidal and retinal vasculatures in the fetal human eye. Prog Retin Eye Res 62:58-76. 10.1016/j.preteyeres.2017.10.001

Lyu Y, Xu W, Zhang J, Li M, Xiang Q, Li Y, Tan T, Ou Q, Zhang J, Tian H, Xu JY, Jin C, Gao F, Wang J, Li W, Rong A, Lu L, and Xu GT. 2020. Protein Kinase A Inhibitor H89 Attenuates Experimental Proliferative Vitreoretinopathy. Invest Ophthalmol Vis Sci 61:1. 10.1167/iovs.61.2.1

Machemer R, and Laqua H. 1975. Pigment epithelium proliferation in retinal detachment (massive periretinal proliferation). American journal of ophthalmology 80.

Maminishkis A, Chen S, Jalickee S, Banzon T, Shi G, Wang FE, Ehalt T, Hammer JA, and Miller SS. 2006. Confluent monolayers of cultured human fetal retinal pigment epithelium exhibit morphology and physiology of native tissue. Invest Ophthalmol Vis Sci 47:3612-3624. 10.1167/iovs.05-1622

Mateos MV, Kamerbeek CB, Giusto NM, and Salvador GA. 2014. The phospholipase D pathway mediates the inflammatory response of the retinal pigment epithelium. Int J Biochem Cell Biol 55:119-128. 10.1016/j.biocel.2014.08.016

Matoba R, Morizane Y, Shiode Y, Hirano M, Doi S, Toshima S, Araki R, Hosogi M, Yonezawa T, and Shiraga F. 2017.

Peer) reviewing PDF | (2020:06:49749:2:0:NEW 15 Sep 2020) 
693

694

695

696

697

698

699

700

701

702

703

704

705

706

707

708

709

710

711

712

713

714

715

716

717

718

719

720

721

722

723

724

725

726

727

728

729

730

731

732

733
Suppressive effect of AMP-activated protein kinase on the epithelial-mesenchymal transition in retinal pigment epithelial cells. PLoS One 12:e0181481. 10.1371/journal.pone.0181481

Miller CG, Budoff G, Prenner JL, and Schwarzbauer JE. 2017. Minireview: Fibronectin in retinal disease. Exp Biol Med (Maywood) 242:1-7. 10.1177/1535370216675245

Miller CG, Pozzi A, Zent R, and Schwarzbauer JE. 2014. Effects of high glucose on integrin activity and fibronectin matrix assembly by mesangial cells. Mol Biol Cell 25:2342-2350. 10.1091/mbc.E14-03-0800

Miralles F, Posern G, Zaromytidou Al, and Treisman R. 2003. Actin dynamics control SRF activity by regulation of its coactivator MAL. Cell 113:329-342. 10.1016/s0092-8674(03)00278-2

Mitry D, Awan MA, Borooah S, Siddiqui MA, Brogan K, Fleck BW, Wright A, Campbell H, Singh J, Charteris DG, and Yorston D. 2012. Surgical outcome and risk stratification for primary retinal detachment repair: results from the Scottish Retinal Detachment study. Br J Ophthalmol 96:730-734. 10.1136/bjophthalmol-2011-300581

Morescalchi F, Duse S, Gambicorti E, Romano MR, Costagliola C, and Semeraro F. 2013. Proliferative vitreoretinopathy after eye injuries: an overexpression of growth factors and cytokines leading to a retinal keloid. Mediators Inflamm 2013:269787. 10.1155/2013/269787

Mudhar HS. 2020. A brief review of the histopathology of proliferative vitreoretinopathy (PVR). Eye (Lond) 34:246250. 10.1038/s41433-019-0724-4

Nassar K, Grisanti S, Tura A, Lüke J, Lüke M, Soliman M, and Grisanti S. 2014. A TGF- $\beta$ receptor 1 inhibitor for prevention of proliferative vitreoretinopathy. Exp Eye Res 123:72-86. 10.1016/j.exer.2014.04.006

Naylor A, Hopkins A, Hudson N, and Campbell M. 2019. Tight Junctions of the Outer Blood Retina Barrier. Int J Mol Sci 21. 10.3390/ijms21010211

Nelson WJ, and Nusse R. 2004. Convergence of Wnt, beta-catenin, and cadherin pathways. Science 303:1483-1487. 10.1126/science.1094291

Ni Y, Qin Y, Huang Z, Liu F, Zhang S, and Zhang Z. 2020. Distinct Serum and Vitreous Inflammation-Related Factor Profiles in Patients with Proliferative Vitreoretinopathy. Adv Ther. 10.1007/s12325-020-01325-x

Niessen CM. 2007. Tight junctions/adherens junctions: basic structure and function. J Invest Dermatol 127:25252532. 10.1038/sj.jid.5700865

Orlova VV, Economopoulou M, Lupu F, Santoso S, and Chavakis T. 2006. Junctional adhesion molecule-C regulates vascular endothelial permeability by modulating VE-cadherin-mediated cell-cell contacts. J Exp Med 203:2703-2714. 10.1084/jem.20051730

Ozal SA, Gurlu V, Turkekul K, Guclu H, and Erdogan S. 2020. Neferine inhibits epidermal growth factor-induced proliferation and migration of retinal pigment epithelial cells through downregulating p38 MAPK and PI3K/AKT signalling. Cutan Ocul Toxicol 39:97-105. 10.1080/15569527.2020.1730882

Palma-Nicolás JP, and López-Colomé AM. 2013. Thrombin induces slug-mediated E-cadherin transcriptional repression and the parallel up-regulation of $\mathrm{N}$-cadherin by a transcription-independent mechanism in RPE cells. J Cell Physiol 228:581-589. 10.1002/jcp.24165

Parrales A, López E, Lee-Rivera I, and López-Colomé AM. 2013. ERK1/2-dependent activation of mTOR/mTORC1/p70S6K regulates thrombin-induced RPE cell proliferation. Cell Signal 25:829-838. 10.1016/j.cellsig.2012.12.023

Pastor JC, Rojas J, Pastor-Idoate S, Di Lauro S, Gonzalez-Buendia L, and Delgado-Tirado S. 2016. Proliferative vitreoretinopathy: A new concept of disease pathogenesis and practical consequences. Prog Retin Eye Res 51:125-155. 10.1016/j.preteyeres.2015.07.005

Peer) reviewing PDF | (2020:06:49749:2:0:NEW 15 Sep 2020) 
734

735

736

737

738

739

740

741

742

743

744

745

746

747

748

749

750

751

752

753

754

755

756

757

758

759

760

761

762

763

764

765

766

767

768

769

770

771

772

773

774

Pei D, Shu X, Gassama-Diagne A, and Thiery JP. 2019. Mesenchymal-epithelial transition in development and reprogramming. Nat Cell Biol 21:44-53. 10.1038/s41556-018-0195-z

Pennock S, Haddock L, Eliott D, Mukai S, and Kazlauskas A. 2014. Is neutralizing vitreal growth factors a viable strategy to prevent proliferative vitreoretinopathy? Prog Retin Eye Res 40:16-34. 10.1016/j.preteyeres.2013.12.006

Pennock S, Rheaume MA, Mukai S, and Kazlauskas A. 2011. A novel strategy to develop therapeutic approaches to prevent proliferative vitreoretinopathy. Am J Pathol 179:2931-2940. 10.1016/j.ajpath.2011.08.043

Rosenthal R, Günzel D, Theune D, Czichos C, Schulzke JD, and Fromm M. 2017. Water channels and barriers formed by claudins. Ann N Y Acad Sci 1397:100-109. 10.1111/nyas.13383

Ruiz-Loredo AY, López E, and López-Colomé AM. 2011. Thrombin promotes actin stress fiber formation in RPE through Rho/ROCK-mediated MLC phosphorylation. J Cell Physiol 226:414-423. 10.1002/jcp.22347

Schiff L, Boles NC, Fernandes M, Nachmani B, Gentile R, and Blenkinsop TA. 2019. P38 inhibition reverses TGF $\beta 1$ and TNF a -induced contraction in a model of proliferative vitreoretinopathy. Commun Biol 2:162. 10.1038/s42003-019-0406-6

Shi J, Barakat M, Chen D, and Chen L. 2018. Bicellular Tight Junctions and Wound Healing. Int J Mol Sci 19. 10.3390/ijms19123862

Shin K, Fogg VC, and Margolis B. 2006. Tight junctions and cell polarity. Annu Rev Cell Dev Biol 22:207-235. 10.1146/annurev.cellbio.22.010305.104219

Shu DY, Butcher E, and Saint-Geniez M. 2020. EMT and EndMT: Emerging Roles in Age-Related Macular Degeneration. Int J Mol Sci 21. 10.3390/ijms21124271

Shu DY, and Lovicu FJ. 2017. Myofibroblast transdifferentiation: The dark force in ocular wound healing and fibrosis. Prog Retin Eye Res 60:44-65. 10.1016/j.preteyeres.2017.08.001

Shukal D, Bhadresha K, Shastri B, Mehta D, Vasavada A, and Johar K, Sr. 2020. Dichloroacetate prevents TGF $\beta$ induced epithelial-mesenchymal transition of retinal pigment epithelial cells. Exp Eye Res 197:108072. 10.1016/j.exer.2020.108072

Skrypek N, Goossens S, De Smedt E, Vandamme N, and Berx G. 2017. Epithelial-to-Mesenchymal Transition: Epigenetic Reprogramming Driving Cellular Plasticity. Trends Genet 33:943-959. 10.1016/j.tig.2017.08.004

Sluysmans S, Vasileva E, Spadaro D, Shah J, Rouaud F, and Citi S. 2017. The role of apical cell-cell junctions and associated cytoskeleton in mechanotransduction. Biol Cell 109:139-161. 10.1111/boc.201600075

Sonoda S, Spee C, Barron E, Ryan SJ, Kannan R, and Hinton DR. 2009. A protocol for the culture and differentiation of highly polarized human retinal pigment epithelial cells. Nat Protoc 4:662-673. 10.1038/nprot.2009.33

Stern J, and Temple S. 2015. Retinal pigment epithelial cell proliferation. Exp Biol Med (Maywood) 240:1079-1086. $10.1177 / 1535370215587530$

Stone RC, Pastar I, Ojeh N, Chen V, Liu S, Garzon KI, and Tomic-Canic M. 2016. Epithelial-mesenchymal transition in tissue repair and fibrosis. Cell Tissue Res 365:495-506. 10.1007/s00441-016-2464-0

Strauss O. 2005. The retinal pigment epithelium in visual function. Physiol Rev 85:845-881. 10.1152/physrev.00021.2004

Takahashi E, Haga A, and Tanihara H. 2015. Merlin Regulates Epithelial-to-Mesenchymal Transition of ARPE-19 Cells via TAK1-p38MAPK-Mediated Activation. Invest Ophthalmol Vis Sci 56:2449-2458. 10.1167/iovs.14-16300

Takahashi E, Nagano O, Ishimoto T, Yae T, Suzuki Y, Shinoda T, Nakamura S, Niwa S, Ikeda S, Koga H, Tanihara H, and Saya H. 2010. Tumor necrosis factor-alpha regulates transforming growth factor-beta-dependent epithelial-

Peer) reviewing PDF | (2020:06:49749:2:0:NEW 15 Sep 2020) 
mesenchymal transition by promoting hyaluronan-CD44-moesin interaction. J Biol Chem 285:4060-4073. 10.1074/jbc.M109.056523

Tamiya S, and Kaplan HJ. 2016. Role of epithelial-mesenchymal transition in proliferative vitreoretinopathy. Exp Eye Res 142:26-31. 10.1016/j.exer.2015.02.008

Tamiya S, Liu L, and Kaplan HJ. 2010. Epithelial-mesenchymal transition and proliferation of retinal pigment epithelial cells initiated upon loss of cell-cell contact. Invest Ophthalmol Vis Sci 51:2755-2763. 10.1167/iovs.09-4725

Tan X, Chen C, Zhu Y, Deng J, Qiu X, Huang S, Shang F, Cheng B, and Liu Y. 2017. Proteotoxic Stress Desensitizes TGFbeta Signaling Through Receptor Downregulation in Retinal Pigment Epithelial Cells. Curr Mol Med 17:189199. 10.2174/1566524017666170619113435

Tarau IS, Berlin A, Curcio CA, and Ach T. 2019. The Cytoskeleton of the Retinal Pigment Epithelium: from Normal Aging to Age-Related Macular Degeneration. Int J Mol Sci 20. 10.3390/ijms20143578

Tomasek JJ, Gabbiani G, Hinz B, Chaponnier C, and Brown RA. 2002. Myofibroblasts and mechano-regulation of connective tissue remodelling. Nat Rev Mol Cell Biol 3:349-363. 10.1038/nrm809

Tosi GM, Marigliani D, Romeo N, and Toti P. 2014. Disease pathways in proliferative vitreoretinopathy: an ongoing challenge. J Cell Physiol 229:1577-1583. 10.1002/jcp.24606

Traweger A, Fuchs R, Krizbai IA, Weiger TM, Bauer HC, and Bauer H. 2003. The tight junction protein ZO-2 localizes to the nucleus and interacts with the heterogeneous nuclear ribonucleoprotein scaffold attachment factorB. J Biol Chem 278:2692-2700. 10.1074/jbc.M206821200

Tsapara A, Luthert P, Greenwood J, Hill CS, Matter K, and Balda MS. 2010. The RhoA activator GEF-H1/LfC is a transforming growth factor-beta target gene and effector that regulates alpha-smooth muscle actin expression and cell migration. Mol Biol Cell 21:860-870. 10.1091/mbc.e09-07-0567

Vietor I, Bader T, Paiha K, and Huber LA. 2001. Perturbation of the tight junction permeability barrier by occludin loop peptides activates beta-catenin/TCF/LEF-mediated transcription. EMBO Rep 2:306-312. 10.1093/embo-reports/kve066

Vigneswara V, Esmaeili M, Deer L, Berry M, Logan A, and Ahmed Z. 2015. Eye drop delivery of pigment epitheliumderived factor-34 promotes retinal ganglion cell neuroprotection and axon regeneration. Mol Cell Neurosci 68:212-221. 10.1016/j.mcn.2015.08.001

Wang FE, Zhang C, Maminishkis A, Dong L, Zhi C, Li R, Zhao J, Majerciak V, Gaur AB, Chen S, and Miller SS. 2010. MicroRNA-204/211 alters epithelial physiology. Faseb j 24:1552-1571. 10.1096/fj.08-125856

Wang L, Dong F, Reinach PS, He D, Zhao X, Chen X, Hu DN, and Yan D. 2016. MicroRNA-182 Suppresses HGF/SFInduced Increases in Retinal Pigment Epithelial Cell Proliferation and Migration through Targeting c-Met. PLoS One 11:e0167684. 10.1371/journal.pone.0167684

Wang L, Lu W, Gao Y-H, Yan H-J, Pei F, Liu X-E, and Zhuang H. 2019. Anluohuaxianwan alleviates carbon tetrachlorideinduced hepatic fibrosis in rats through upregulation of peroxisome proliferator-activated receptor-Gamma and downregulation of nuclear factor-Kappa B/I\&\#954;B\&\#945; signaling pathway. World Journal of Traditional Chinese Medicine 5:95-103. 10.4103/wjtcm.wjtcm_16_19

Wheelock MJ, and Johnson KR. 2003. Cadherins as modulators of cellular phenotype. Annu Rev Cell Dev Biol 19:207235. 10.1146/annurev.cellbio.19.011102.111135

Wickham L, Ho-Yen GO, Bunce C, Wong D, and Charteris DG. 2011. Surgical failure following primary retinal detachment surgery by vitrectomy: risk factors and functional outcomes. Br J Ophthalmol 95:1234-1238. 10.1136/bjo.2010.190306 
816

817

818

819

820

821

822

823

824

825

826

827

828

829

830

831

832

833

834

835

836

837

838

839

840

841

842

843

844

845

846

847

848

849

850

851

852

853

854

855

856

Wubben TJ, Besirli CG, and Zacks DN. 2016. Pharmacotherapies for Retinal Detachment. Ophthalmology 123:15531562. 10.1016/j.ophtha.2016.02.040

Xiao W, Chen X, Liu X, Luo L, Ye S, and Liu Y. 2014. Trichostatin A, a histone deacetylase inhibitor, suppresses proliferation and epithelial-mesenchymal transition in retinal pigment epithelium cells. I Cell Mol Med 18:646-655. 10.1111/jcmm.12212

Yang J, Antin P, Berx G, Blanpain C, Brabletz T, Bronner M, Campbell K, Cano A, Casanova J, Christofori G, Dedhar S, Derynck R, Ford HL, Fuxe J, García de Herreros A, Goodall GJ, Hadjantonakis AK, Huang RJY, Kalcheim C, Kalluri R, Kang Y, Khew-Goodall Y, Levine H, Liu J, Longmore GD, Mani SA, Massagué J, Mayor R, McClay D, Mostov KE, Newgreen DF, Nieto MA, Puisieux A, Runyan R, Savagner P, Stanger B, Stemmler MP, Takahashi Y, Takeichi M, Theveneau E, Thiery JP, Thompson EW, Weinberg RA, Williams ED, Xing J, Zhou BP, and Sheng G. 2020. Guidelines and definitions for research on epithelial-mesenchymal transition. Nat Rev Mol Cell Biol 21:341-352. 10.1038/s41580-020-0237-9

Yang S, Yao H, Li M, Li H, and Wang F. 2016. Long Non-Coding RNA MALAT1 Mediates Transforming Growth Factor Beta1-Induced Epithelial-Mesenchymal Transition of Retinal Pigment Epithelial Cells. PLoS One 11:e0152687. 10.1371/journal.pone.0152687

Yang X, Chung JY, Rai U, and Esumi N. 2018. Cadherins in the retinal pigment epithelium (RPE) revisited: P-cadherin is the highly dominant cadherin expressed in human and mouse RPE in vivo. PLoS One 13:e0191279. 10.1371/journal.pone.0191279

Yao H, Ge T, Zhang Y, Li M, Yang S, Li H, and Wang F. 2019. BMP7 antagonizes proliferative vitreoretinopathy through retinal pigment epithelial fibrosis in vivo and in vitro. Faseb j 33:3212-3224. 10.1096/fj.201800858RR

Yokoyama K, Kimoto K, Itoh Y, Nakatsuka K, Matsuo N, Yoshioka H, and Kubota T. 2012. The PI3K/Akt pathway mediates the expression of type I collagen induced by TGF- $\beta 2$ in human retinal pigment epithelial cells. Graefes Arch Clin Exp Ophthalmol 250:15-23. 10.1007/s00417-011-1766-x

Zhang C, Su L, Huang L, and Song ZY. 2018a. GSK3 $\beta$ inhibits epithelial-mesenchymal transition via the Wnt/ $\beta$ catenin and PI3K/Akt pathways. Int J Ophthalmol 11:1120-1128. 10.18240/ijo.2018.07.08

Zhang J, Yuan G, Dong M, Zhang T, Hua G, Zhou Q, and Shi W. 2017. Notch signaling modulates proliferative vitreoretinopathy via regulating retinal pigment epithelial-to-mesenchymal transition. Histochem Cell Biol 147:367-375. 10.1007/s00418-016-1484-x

Zhang L, Dong Y, Wang Y, Gao J, Lv J, Sun J, Li M, Wang M, Zhao Z, Wang J, and Xu W. 2019. Long non-coding RNAs in ocular diseases: new and potential therapeutic targets. Febs $j$ 286:2261-2272. 10.1111/febs.14827

Zhang P, Zhao G, Ji L, Yin J, Lu L, Li W, Zhou G, Chaum E, and Yue J. 2018b. Knockdown of survivin results in inhibition of epithelial to mesenchymal transition in retinal pigment epithelial cells by attenuating the TGF $\beta$ pathway. Biochem Biophys Res Commun 498:573-578. 10.1016/j.bbrc.2018.03.021

Zhang Y, Zhao D, Yang S, Yao H, Li M, Zhao C, Zhang J, Xu GT, Li H, and Wang F. 2018c. Protective Effects of Fucoidan on Epithelial-Mesenchymal Transition of Retinal Pigment Epithelial Cells and Progression of Proliferative Vitreoretinopathy. Cell Physiol Biochem 46:1704-1715. 10.1159/000489246

Zhou M, Geathers JS, Grillo SL, Weber SR, Wang W, Zhao Y, and Sundstrom JM. 2020. Role of Epithelial-Mesenchymal Transition in Retinal Pigment Epithelium Dysfunction. Front Cell Dev Biol 8:501. 10.3389/fcell.2020.00501

Zhou RM, Wang XQ, Yao J, Shen Y, Chen SN, Yang H, Jiang Q, and Yan B. 2015. Identification and characterization of proliferative retinopathy-related long noncoding RNAs. Biochem Biophys Res Commun 465:324-330. 10.1016/j.bbrc.2015.07.120

Peer] reviewing PDF | (2020:06:49749:2:0:NEW 15 Sep 2020) 
857 Zhou X, Kuang X, Long C, Liu W, Tang Y, Liu L, Liu H, He J, Huang Z, Fan Y, Zhang Q, and Shen H. 2017. Curcumin $858 \quad$ Inhibits Proliferation and Epithelial-Mesenchymal Transition of Retinal Pigment Epithelial Cells Via Multiple

859 Pathways. Curr Mol Med 17:312-319. 10.2174/1566524017666171106115655

860

861 


\section{Figure 1}

Role of cell-cell contact in health and PVR

(A)Tight junctions and adherens junctions maintain cell-cell contact and cell polarity in RPE cells. Mature RPE cells with cell-cell contact remain dormant by sequestering EMT effectors to prevent nuclear localization. ZO-1 sequesters nucleic acid-binding protein (ZONAB) at tight junctions/cytoplasm, and adherens junctions sequester $\beta$-catenin by binding to epithelial cadherins. Tight junctions have a barrier function that control the passage of solutes. (B)Loss of cell-cell contact initiates EMT. Deconstruction of junctional complexes or reduction of epithelial cadherins/ZO-1 elicits nuclear localization of ZONAB/ $\beta$-catenin and activation of their target genes, and disrupts the outer blood retinal barrier, facilitating the release of growth factors and cytokines, which further aggravate PVR. 
A

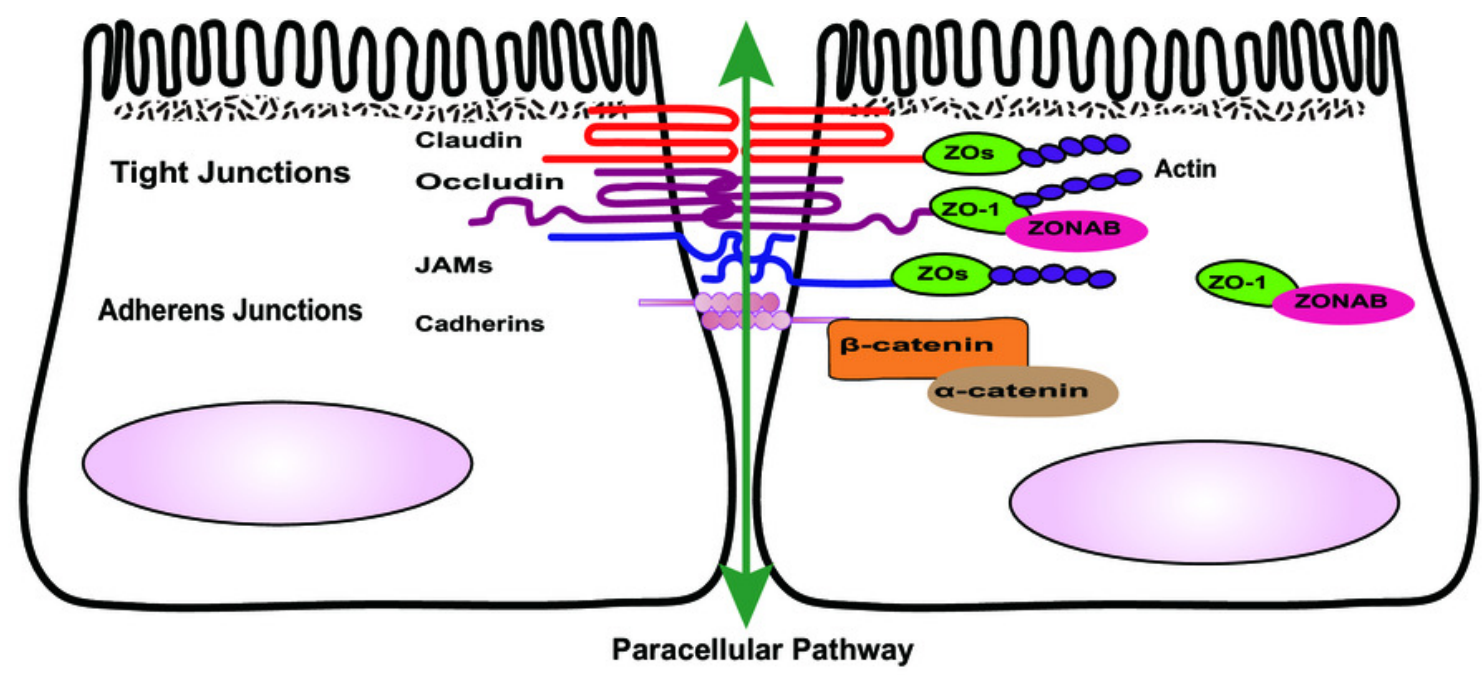

B

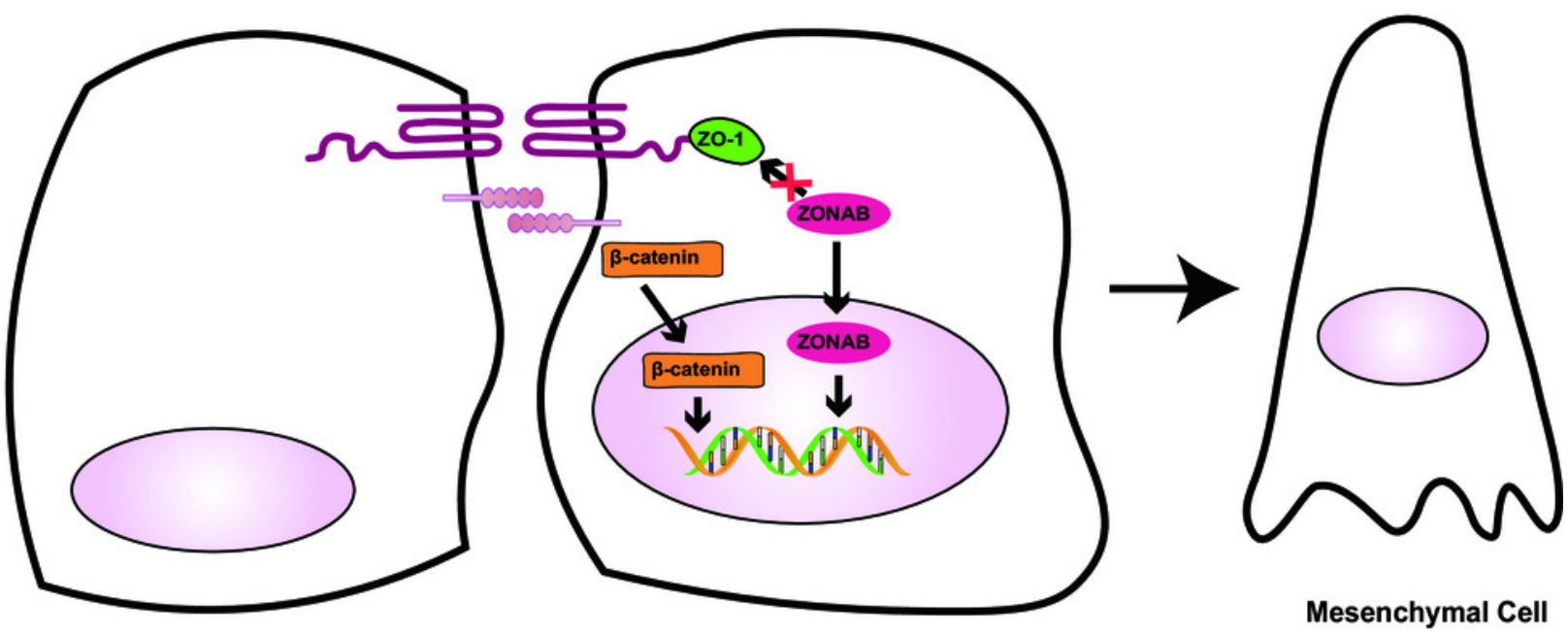


Figure 2

Signaling pathways of TGF- $\beta$-induced RPE cells EMT

Transforming growth factor- $\beta$ (TGF- $\beta$ ) activates various signaling pathways that cooperate to cause EMT. Besides canonical SMAD-dependent signaling, TGF- $\beta$ can activate the Rho, PI3K/AKT, ERK MAPK, p38 MAPK, JUN N-terminal kinase (JNK) and nuclear factor-KB (NF-KB) pathways.

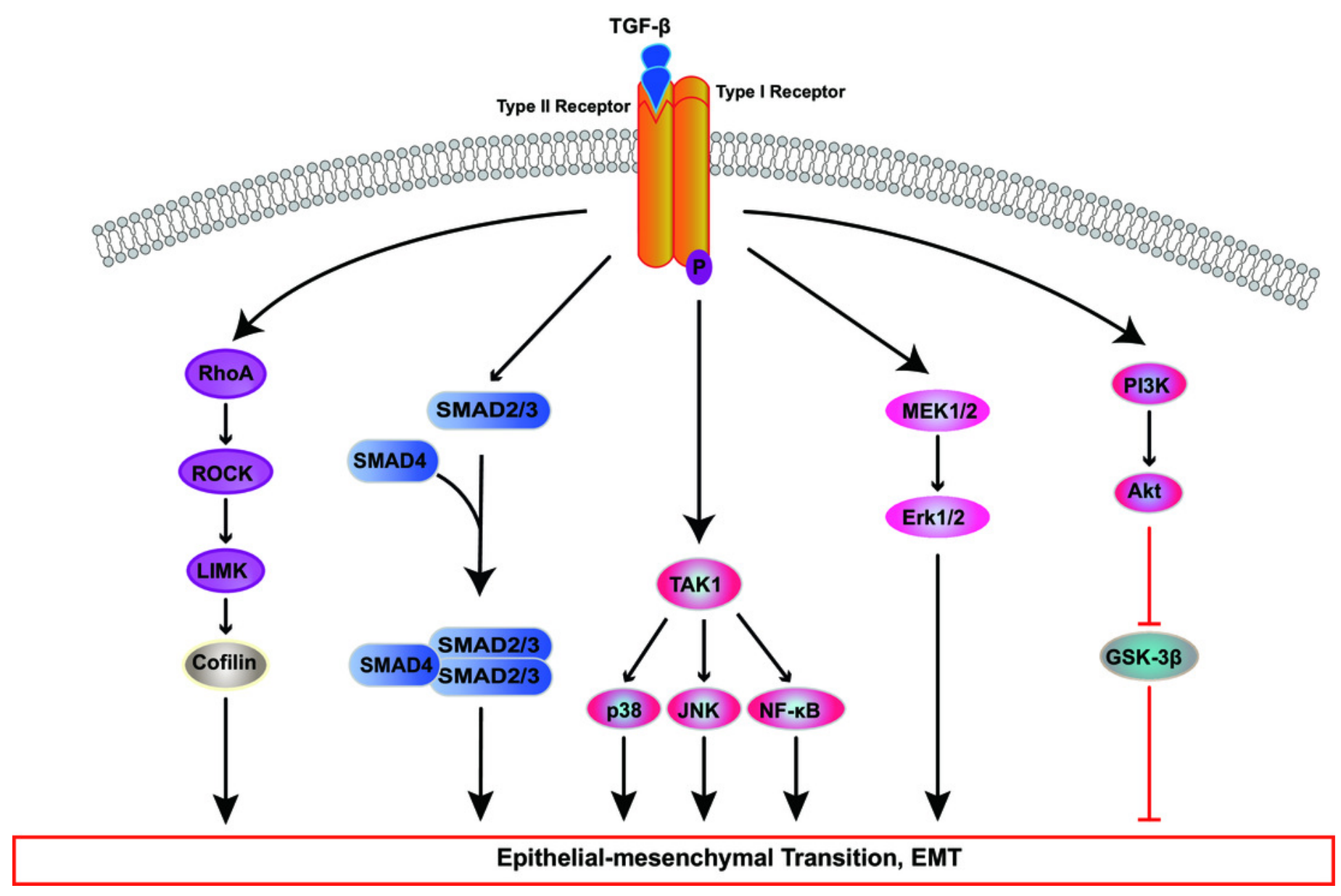




\section{Figure 3}

RTK, Wnt, Notch, and Thrombin signaling in RPE cells EMT

Growth factors (GFs) stimulate receptor tyrosine kinases (RTKs) and induce EMT through

PI3K-AKT and ERK MAPK signaling pathways. Thrombin activates PI3K and Rho signaling. PI3K promote EMT through Akt and mTOR pathways. WNT signaling promotes EMT by inhibiting

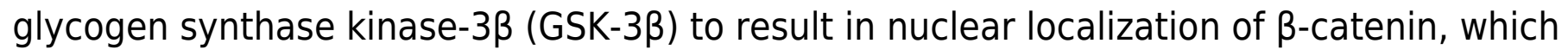
interact with the transcription factors lymphoid enhancer factor (LEF) $/ T$ cell factor (TCF) and change genes expression. The intercellular interaction of Jagged ligands with Notch receptors induces EMT through the cleavage and release of the Notch ICD, which then activate target genes. 


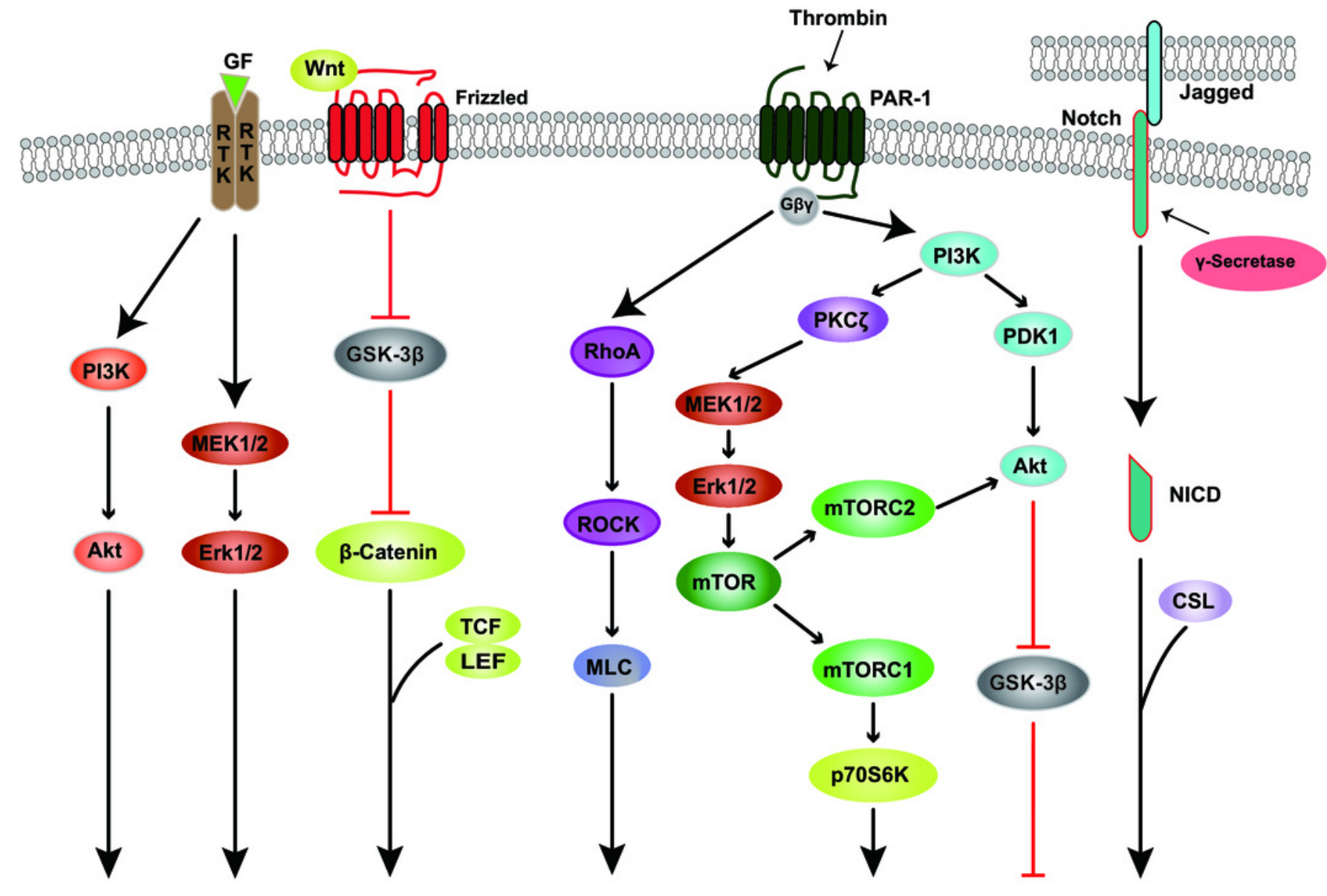

Epithelial-mesenchymal Transition,EMT 